\title{
O trabalho histórico na sala de aula
}

\author{
Maria Auxiliadora Schmidt \\ Tânia Braga Garcia ${ }^{1}$
}

\section{RESUMO}

Qual o lugar e o significado da pesquisa na formação do professor? Que sentido e utilidade tem a pesquisa na prática cotidiana do professor de História? Este texto apresenta reflexões sobre estas temáticas, relatando resultados parciais de pesquisas, cujo objetivo geral é recuperar o processo de construção do método de ensino de História, a partir do diálogo entre a Didática Geral (Develay, 1999; André, 1995) e a Didática Específica da História (Prats, 2001; Moniot, 1993; Bergman,1990 e Rusen, 1987). Estes resultados enfocam alguns elementos dos estudos realizados no âmbito da pesquisa bibliográfica, o que permitiu apontar indícios de como a temática é vista pela literatura destinada à formação de professores; e na perspectiva do trabalho de campo, o que produziu subsídios para reflexões acerca da prática cotidiana do professor de História, concretizado no projeto Recriando Histórias, o qual vem sendo desenvolvido pelas pesquisadoras em escolas da região metropolitana de Curitiba, desde 1997. Para já, os resultados permitem reafirmar o pressuposto de que, transmitir conteúdos e assumir a perspectiva da investigação não são alternativas excludentes.

Palavras-chave: Ensino de história, didática, história local, formação de professores

Trata-se de organizar o trabalho histórico em sala de aula. 0 trabalho consiste então em uma pesquisa. Mas uma pesquisa de que? E como esta pesquisa poderá ser feita? (Roger Cousinet, 1922)

Em sua obra sobre ensino de História, apresentada em 1922, Roger Cousinet já indica orientações para o professor trabalhar o método de pesquisa da História em sala de aula, enfatizando, principalmente, o uso de documentos

1 Pesquisadoras e professoras do Programa de Pós-Graduação em Educação da Universidade Federal do Paraná, Linha de Pesquisa Saberes, Cultura e Práticas Escolares. 
históricos. Esta obra somente foi publicada na França em 1950, tendo circulado no Brasil como componente de algumas bibliotecas escolares.

No entanto, pesquisas realizadas em manuais de didática da história, destinado ao uso de professores no Brasil têm indicado que não existe a incorporação da pesquisa, ou seja, da metodologia da produção do conhecimento histórico no ensino de História ${ }^{2}$, o que permite apontar a existência de um ocultamento do método da própria ciência.

Para Zaragoza (1989) de todas as disciplinas do currículo escolar, a Históriaé, talvez, a que oculta com maior intensidade a sua própria metodologia e se apresenta como um conhecimento inalterável e acumulativo. É por isto que, raras vezes, se oferece ao aluno uma dimensão historiográfica da problemática do passado. Neste sentido, diz o autor, "ao ocultar a metodologia se oculta a historicidade da ciência, e a História se converte em dogma". (ZARAG0ZA, 1989, p. 168). Isto ocorreria, em sua opinião, por razões de ordem política, ou seja, a função de justificar regimes políticos que o ensino de História tem tido em alguns casos; de ordem ideológica, na qual o ensino de História submeteu-se a determinados modelos de interpretação; razões científicas, considerando-se a complexidade e ambigüidade da própria epistemologia da História, bem como sua indeterminação, o que resultaria em dificuldades de compreensão por parte dos alunos; razões profissionais, resultantes da própria formação dos docentes, a qual não tem incorporado hábitos de pesquisa relacionados com o ensino. Finalmente, razões didáticas, devido à precariedade da incorporação dos avanços da própria didática específica da ciência de referência.

Na perspectiva deste autor, devido à especificidade da História e de sua didática, o conhecimento e a prática da investigação estão indissoluvelmente ligados à construção do pensamento sócio-histórico. É nesta direção que ele defende a "presença da investigação no método de ensino da História, como um fator imprescindível na formação do pensamento histórico do adolescente", na medida em que a pesquisa pode despertar o interesse do aluno pelo

\footnotetext{
2 Estas pesquisas relacionadas à análise dos manuais destinados à formação do professor de História constituem parte do projeto "Ensinar a Ensinar: identificação e análise de manuais destinados à formação de professores no Brasil", vinculado ao projeto Manes/Uned/Madri. Este projeto tem sido coordenado pelas autoras, dentro da linha de pesquisa Saberes, cultura e práticas escolares, do PPGE-UFPR.
} 
conhecimento histórico e tornar-se o processo pelo qual ele adquire os princípios que regem a produção deste conhecimento. Neste sentido, não se trata de converter os alunos em historiadores, nem tampouco que se despreze 0 conhecimento já elaborado, ou seja, a consciência que uma sociedade tem e quer transmitir sobre a sua evolução histórico. Trata-se, sim, de que o aluno chegue a interiorizar alguns princípios, tais como: que a História é uma ciência com uma metodologia própria e que muda com o tempo; que o conhecimento do passado é sempre parcial e se dá a partir de testemunhos, muitas vezes contraditórios; que existem diversos níveis de análise sobre o passado, bem como diferentes construções conceituais, as quais se denomina historiografia; que os grandes modelos históricos são elaborações a posteriori, a partir de estudos parciais, locais e pontuais; que cada geração e cada indivíduo podem colocar novas questões ou criticar o discurso aceito; que existe uma continuidade conceitual entre a Didática da História e a própria ciência histórica.

A metodologia de ensino baseada na investigação teria, no entender de Zaragoza, a intervenção mediadora do professor, cujo papel seria importante na seleção e graduação da metodologia de trabalho com as fontes, em função dos objetivos a serem atingidos e do desenvolvimento do conhecimento no aluno. Os passos nesta metodologia seriam: o conhecimento sobre o estado atual da questão ou do discurso existente sobre o tema; a colocação de novas questões a partir de problemáticas da atualidade, da cultura e dos interesses dos alunos; a formulação de hipóteses; a análise das fontes disponíveis; o trabalho com as fontes e a formulação de resultados. Não se trata de um trabalho trivial, mas de ter como ponto de partida da investigação o próprio universo do aluno, dando ao conhecimento histórico um sentido ou, como afirma Zaragoza, "a investigação é a pedra de toque da Didática da História, a qual estende entre o passado desconhecido e 0 adolescente, a ponte da ação científica. 0 afetivo pode ser 0 impulso, o motivo, mas a atividade de investigação é cognitiva". (1989, p. 173).

Em outra direção, Iglesias e Perez (1994) também propöen: uma metodologia do ensino de Historia baseada na investigação. Estes autores nartem do pressuposto de que "Uma metodologia se caracteriza pelo tipo de atividades que emprega, pela função e sentido que atribui a cada atividade e pela orientação da sequiência de atividades no decorrer de uma unidade didática" e ainda que "uma diversidade de metodologias responde a diversas concepções de aprendizagem ou, 
dito de outra maneira, qualquer metodologia se fundamenta, explícita ou implicitamente, em uma determinada concepção de como se aprende".

Segundo estes autores, existem duas maneiras predominantes de se aprender/ensinar a História. 0 primeiro modelo é aquele em que cada unidade se desenvolve em torno da explicação do professor e/ou da leitura de livros ou textos, seguida da realização de exercícios práticos ou de aplicação. Neste modelo subjaz a idéia de que se aprende recebendo informações, lendo, escutando e as atividades práticas não têm como função produzir aprendizagens, mas comprovar ou consolidar os conhecimentos. 0 segundo modelo, inclui a explicação e participação do professor para um trabalho com documentos históricos e historiográficos, guiado por questões, para chegar a um objetivo o qual pretende concluir. Este modelo se sustenta sobre uma teoria da aprendizagem que se caracteriza pelo fato de ser a aprendizagem $m$ processo homólogo ao da produção (científica) do conhecimento. Estes dois modelos apresentam sequiências distintas de atividades.

Uma metodologia de ensino baseada na investigação tem como referência o segundo modelo, mas não pode ser confundida com uma metodologia baseada no conhecimento autônomo por parte do aluno, ou um "simulacro da investigação científica na aula". Ainda segundo Iglesias e Perez (1994), é preciso levar em consideração que o processo de aprendizagem escolar e 0 processo de investigação científica ocorrem em contextos absolutamente distintos e, por isto, são distintos. Neste aspecto eles se aproximam de Zaragoza (1989) ao afirmarem que não se trata de transformar os alunos em "pequenos historiadores", "mas de fazer com que aprendam história"(IGLESIAS e PEREZ, 1994, p. 186).

Esta mesma preocupação está presente nos trabalhos de Fines (1996) para quem existem algumas razões pelas quais o ensino de História pode ter caminhos semelhantes ao trabalho do historiador. A principal delas é que, sem conhecer como a história que nós recebemos é produzida, nós somente obtemos uma série de misteriosas asserções sem significado, sem sentido e sem utilidade para quem aprende. Ademais, diz Fines, um bom aprendizado é sempre uma aprendizagem ativa na qual, tanto professores quanto alunos fazem 0 trabalho com as fontes. 0 uso de fontes no ensino de história produz um sentimento de realidade que a chamada história de "segunda mão" raramente produz. 
Enquanto a perspectiva de Zaragoza (1989) pressupõe uma didática da história na qual estão presentes os elementos do método de produção do conhecimento histórico e, por isto, estaria mais adequada aos interesses dos adolescentes, Iglesias e Perez (1994) partem do suposto de que esta metodologia deveria ser um guia orientador para o aluno, no processo de produção do conhecimento, na medida em que o ajudaria a enfrentar situações problemáticas, situações que mobilizam estruturas cognitivas do sujeito individual e os esquemas compartilhados pelo grupo de alunos. Neste sentido, eles apresentam algumas idéias que justificariam uma metodologia do ensino de História baseada na investigação, como: reconhecer a importância que tem a exploração e a curiosidade para a aprendizagem; propiciar o desenvolvimento da autonomia e da criatividade crítica no aluno, dando significado à tensão entre o desenvolvimento individual e social que está presente nas situações de ensino-aprendizagem.

Incorporando a proposta de tomar como ponto de partida as questões problemas, feita por Zaragoza (1989), os autores explicam que, colocar problemas seria gerar uma situação nova, a qual contrastaria com o que é familiar ao aluno e teria a função de estimular a sua "curiosidade científica"; desencadeando processos de reestruturação cognitiva. Aqui, para Iglesias e Perez (1994) surge uma dúvida, qual seja, em que medida os problemas de caráter histórico poderiam interessar realmente aos adolescentes considerando que o conhecimento histórico, via de regra, se refere a uma realidade que não existe, de difícil percepção e pouco significativa socialmente?

Um caminho seria o de partir de problemas históricos, apresentando propostas de aprendizagens que efetivamente possam ser assumidas como problemáticas cognitivas pelos alunos. Estas propostas poderiam ser expressas sob a forma de "objetos de estudos sobre o passado" e "devem ter a característica de fazer referência a realidades perceptíveis, querendo dizer, com isto, que se referem não tanto a realidades "visíveis"para os alunos, mas "disponíveis mentalmente" por parte deles. Mas, ao mesmo tempo, não podem ser propostas triviais, que não sejam capazes de integrar os diversos tipos de conteúdos que se pretende ensinar" (IGLESIAS e PEREZ, 1994, p. 191).

É necessário destacar a importância dada por Iglesias e Perez ao conteúdo a ser trabalhado em sala de aula, ou seja, à indissociabilidade entre a 
metodologia da investigação e a própria organização e seleção dos conteúdos a serem ensinados. Assim, partir de problemas exigiria, por parte do professor, uma seleção adequada de propostas de aprendizagens, gerando situações em aula que permitam serem as problemáticas de aprendizagem assumidas pelos alunos. Para tanto, algumas estratégias seriam imprescindíveis, como aquelas que permitissem gerar curiosidades, motivar situações de conflito cognitivo, colocar em ação concepções dos alunos e questioná-las.Nestes casos, o uso de recursos como projeção de filmes, o trabalho com textos polêmicos ou contraditórios e visitas de estudos seria interessante, pois funcionariam como estratégias motivadoras de interações entre professor e alunos, criando situações adequadas para se abordar o tema a ser estudado.

Alguns cuidados teriam que ser levados em consideração, nesta metodologia de ensino baseada na investigação. Em primeiro lugar, ao serem relevadas as concepções dos alunos, os erros não devem ser objetos de punições, mas pontos de partida para a elaboração de conhecimentos mais complexos. Em segundo, tomar como princípios norteadores, alguns pressupostos da aprendizagem em alunos adolescentes, tais como: o fato dos alunos, quando em situação de aprendizagem na sala de aula, já disporem de explicações que aplicam à interpretação dos fenômenos sociais no passado e no presente; o cuidado em entender que estas idéias podem estar enviesadas pelo componente intencional na explicação histórica, de modo que, em muitos casos, os alunos pensam que a mudança histórica acontece pela ação voluntária de determinados sujeitos; a compreensão de que, em muitos casos, a explicação histórica está marcada pela visão determinista que o aluno tem, no sentido de que aconteceu porque assim teve que acontecer, ou que não se pode precisar as causas porc'le tudo influi em tudo; a presença de determinadas imagens do passado que, tanto alunos e professores têm, as quais interferem em suas análises históricas e a permanência, nos alunos, de diferentes informações sobre fatos históricos que não têm função explicativa para suas vidas cotidianas.

Estas considerações permitem afirmar que as disponibilidades dos alunos em admitirem conhecimentos alternativos, mais próximos ao conhecimento científico, poderão variar conforme se tratar de explicações às quais eles têm mais resistência ou não.

Alguns princípios merecem ser retidos das idéias já enunciadas. 0 primeiro é de que uma metodologia de ensino de História baseada na investigação 
tem como suporte uma concepção de ensino-aprendizagem onde o aluno tem um papel ativo e o professor a função de mediador. Assim, o seu fundamento básico é de que ela se realiza "mediante um processo de indagação, entendido não simplesmente como "fazer perguntas sobre a realidade", quer dizer, questioná-la e problematizá-la, mas também como uma busca de significados a qual exige do sujeito a realização de determinadas operações intelectuais para entender a experiência individual e coletiva". (IGLESIAS e PEREZ, 1994, p. 188).

0 segundo é o de que, além de poder propiciar respostas às questões da vida cotidiana, este tipo de ensino contribuiria para a concretização do trabalho histórico em sala de aula, ou seja, para a produção de um novo tipo de conhecimento o qual pode ser denominado saber histórico escolar, resultado de um determinado processo de didatização e axiologização ${ }^{3}$ do conhecimento.

A partir das reflexões encetadas por Zaragoza (1989) e Iglesias e Perez (1994), pode-se indicar a presença da investigação como uma metodologia para o ensino de História possível e necessária em sala de aula, bem como a perspectiva da formação do professor de História como investigador social.

Dentro deste quadro de reflexões, autores como Manique/Proença (1994); Trepat (1995); Leduc/Marcos-Alvarez/Le Pellec (1998); Barca (2000;2001); Arthur/Phillips (2000); Michaux (1997); Lautier (1997); Haydn/Arthur/Hunt (2001); Bourguignon (1998) e Moniot (1993), também incorporaram os elementos do método de produção do conhecimento histórico sob a forma de propostas de uma didática específica da história, à moda das sugestões feitas por Zaragoza (1989). Neste sentido, o método de investigação histórica tornase inerente ao próprio método de ensino, além de sua utilização como atividade de investigação, tal como sugerida por Iglesias \& Perez (1994), ou sob a forma de projetos de investigação ${ }^{4}$, além de tornar-se um princípio inegociável na formação do professor de História.

As novas perspectivas indicam que recuperação da historicidade do método da História é viável também no cotidiano da sala de aula, na medida em que a aula de História torna-se "o momento em que, ciente do conhecimento

\footnotetext{
3 Uma importante reflexão acerca do saber histórico escolar pode ser encontrada no trabalho de MONTEIRO, Ana Maria Ferreira da Costa. Ensino de História: Entre saberes e práticas. Tese de doutorado. Dpto. De Educação, PPGE-PUC-Rio de Janeiro, 2002.
} 
que possui, o professor pode oferecer a seu aluno a apropriação do conhecimento histórico existente, através de um esforço e de uma atividade com a qual ele retome a atividade que edificou este conhecimento" (SCHMIDT,1998, p. 57) ou, como afirma Prats (2001) o ensino de História requer introduzir o aluno no método histórico, cujos elementos principais que deverão estar presentes em todo o processo didático, são: aprender a formular hipóteses; aprender a classificar e analisar as fontes históricas; aprender a analisar a credibilidade das fontes históricas; aprender relações de causalidade e a construir a explicação histórica.

No sentido de propor situações experienciais na renovação do ensino de História para a escola básica, está sendo desenvolvido o projeto Recriando a História ${ }^{5}$. Neste projeto, partiu-se do pressuposto de que nas situações de ensinoaprendizagem da História podem ocorrer processos com especificidades próprias, mas não excludentes, quais sejam: a incorporação do método de produção do conhecimento histórico como inerente ao processo didático em sala de aula, a utilização da metodologia de investigação histórica como estratégia ou atividade de ensino e o desenvolvimento profissional do professor como investigador de sua própria prática pedagógica.

Entende-se que, ao relatar os procedimentos selecionados e já utilizados para o desenvolvimento do Projeto Recriando a História, é possível apresentar alguns elementos que contribuem para explicar a presença desses dois processos que se revelam, de forma articulada, nas atividades didáticas organizadas com professoras e com alunos envolvidos.

A primeira referência teórica do Projeto, de natureza didática, está relacionada à compreensão de que a organização do ensino deve levar em consideração os conteúdos culturais. Diferentes autores têm defendido essa idéia, com entendimentos diferenciados do que isso significa para o trabalho em sala de aula. No contexto do Projeto, as contribuições de Freire (1967; 1979; 1992) foram tomadas, no sentido de se afirmar que os conteúdos dos

40 trabalho de Projeto como estratégia pedagógica no ensino de História pode ser encontrado em PROENÇA, Maria Cândida. 0 trabalho de Projecto como estratégia pedagógica. Santarém (PA): Escola Superior de Educação, 1993. Ver também FONSECA, Selva Guimarães. Didática e Prática de Ensino de História. Campinas: Papirus, 2003.

50 Projeto Recriando a História é um projeto de ensino, extensão e pesquisa da UFPR, que vem sendo desenvolvido pelas autoras, desde 1997 e envolve um trabalho conjunto com alunos de graduação (bolsistas) e professores da rede pública de ensino. 
processos pedagógicos, no ensino e na aprendizagem, devem ser constituídos a partir da identificação, nos contextos locais e também em âmbitos mais amplos, das diversidades e desigualdades que compõem a realidade social, e que se expressam e são compreendidos de diferentes formas pelos sujeitos.

A segunda referência, do campo da historiografia, está relacionada à concepção que entende 0 ensino da História como estudo da experiência humana no tempo, na perspectiva de Thompson (1981). Essa perspectiva permite dar aos conteúdos de ensino um tratamento temático, na direção de se procurar recuperar o sentido das experiências individuais e coletivas que dizem respeito aos temas e, assim, contribuir para a formação das identidades.

Ainda do ponto de vista da ciência da referência - a História, alguns aspectos metodológicos foram tomados como relevantes para 0 desenvolvimento do trabalho no projeto. 0 primeiro deles diz respeito ao destaque dado à História Local em algumas produções historiográficas, fato que tem levado a uma supervalorização desta perspectiva nas propostas curriculares nacionais, constituindo-se como um dos novos ídolos do ensino de História. (ROMERO, 1998).

Algumas ilusões estariam alimentando a construção deste novo ídolo, como a idéia de que a realidade imediata é útil e importante para a motivação do conhecimento e atua eficazmente como motivadora de problematizações. Esta questão advém muito mais de elaborações do senso comum e da transposição mecânica de teorias de aprendizagem do que de reflexões mais científicas sobre 0 tema.

É importante observar que uma realidade local não contém, em si mesma, as chaves de sua própria explicação. Ademais, ao se propor o ensino de História Local como indicador da construção de identidades, não se pode esquecer de que, no processo de mundialização que se vive, é absolutamente indispensável que a construção de identidades tenha marcos de referência relacionais, os quais devem ser conhecidos e situados: o local, o regional, o nacional, o latinoamericano, o mundial (ROMERO, 1998).

Estas questões são indiciárias de que, enquanto definição curricular para o ensino, a História Local traz uma maneira bastante complexa de pensar e fazer a História, em termos de aprendizagens e concepções. Tal ordem de questões torna-se mais grave ao se levar em consideração os perigos do 
anacronismo, do desenvolvimento de perspectivas etnocêntricas, reducionismos localistas, bem como o perigo de identificação do local com o mais próximo, 0 mais conhecido, estabelecendo-se uma relação mecânica entre o próximo e 0 conhecido.

Enquanto elemento constitutivo da transposição didática do saber histórico em saber histórico escolar, tendo como referência a perspectiva da prática social, a História Local pode ser vista como uma estratégia de ensino (OSSANA, 1994). Trata-se de uma forma de abordar a aprendizagem, a construção e a compreensão do conhecimento histórico, a partir de proposições que tenham a ver com os interesses dos alunos, suas aproximações cognitivas e afetivas, sua vivência cultural, com as possibilidades de desenvolver atividades vinculadas diretamente com a vida cotidiana, entendida como expressão concreta de problemas mais amplos. Enquanto estratégia de aprendizagem, o trabalho com a História Local pode garantir controles epistemológicos do conhecimento histórico, a partir de recortes selecionados e integrados ao conjunto do conhecimento. Entre as suas possibilidades, segundo Ossana (1994), destacam-se as seguintes:

1. o trabalho com o local pode produzir a inserção do aluno na comunidade da qual ele faz parte, criar a sua própria historicidade e produzir a identificação de si mesmo e também do seu redor, dentro da História, levando-o a compreender como se constitui e se desenvolve a sua historicidade em relação aos demais, entendendo quanto há de História em sua vida, construída por ele mesmo, e quanto tem a ver com elementos externos a ele - próximos/ distantes; pessoais/estruturais; temporais/espaciais;

2. esse trabalho possibilita gerar atividades e atitudes investigativas, criadas a partir de realidades cotidianas - por exemplo, o trabalho com documentos e materiais auxiliares - e permite, também, buscar informações nos arquivos, como os próprios arquivos familiares e perguntar-se sobre 0 sentid0o das coisas;

3. pode facilitar a inserção em atividades que possibilitem trabalhar com diferentes níveis de análises - econômica, social, política, cultural -, já que no âmbito mais reduzido sua abordagem fica mais clara, as diferenças de ritmos, sua articulação e desarticulação ficam mais acentuadas, além da especificidade do vocabulário de cada um destes níveis poder ser melhor explicitado; 
4. 0 trabalho a partir de recortes menores pode facilitar o estabelecimento de continuidades e diferenças, evidências de mudanças, dos conflitos e das permanências.

Ainda, segundo Ossana (1994), o trabalho com a História Local no ensino pode ser um instrumento idôneo para a construção de uma História mais plural, menos homogênea, que não silencie as especificidades. 0 local ou o regional, instituídos como objetos de estudo, podem ser contrastados com outros âmbitos e indicar a pluralidade em dois sentidos: na possibilidade de se ver mais de uma história ou mais de um eixo na própria história do lugar, ou na possibilidade de se ver outras histórias micro, partes, todas elas, de alguma outra história que as englobe e, ao mesmo tempo, que reconheça suas particularidades.

Esse trabalho pode também facilitar a construção de problematizações, a apreensão de várias histórias lidas a partir de distintos sujeitos históricos, bem como de histórias silenciadas, histórias que não tiveram acesso à própria História. Ele favorece, assim, a recuperação da vivência pessoal e coletiva dos alunos, bem como possibilita que eles se vejam como participantes da realidade histórica, a qual deve ser analisada e retrabalhada, com o objetivo de converte-la em conheciment" histórico, em autoconhecimento, pois, "desta maneira, podem inserir-se a partir de um pertencimento, numa ordem de vivências múltiplas e contrapostas no espaço nacional e internacional"(OSSANA, 1994).

Enquanto estratégia pedagógica, o trabalho com a História Local no ensino de História indica algumas possibilidades ou estratégias, como a exploração de arquivos locais, do patrimônio, da estatuária, da toponímia e da imprensa local.

Ao lado disso, considerou-se a possibilidade de uso, no ensino, dos documentos em estado de arọuivo familiar (ARTIÈRES, 1998; GERMINARI, 2001). Tais documentos "não fazem parte da vida de pessoas que tiveram algum destaque público no cenário político, ou realizaram algo "importante"para a sociedade (...) podem ser encontrados no interior das mais diversas residências, arquivados em gavetas em caixas de papelão, esquecidas temporariamente em cima de armários"(GERMINARI, 2001, p. 18).

A partir dessas referências, o trabalho no Projeto Recriando a História foi desenvolvido, na perspectiva de recriar o conteúdo histórico, problematizando-o a partir de elementos da cultura. As expressões recontar, 
recriar, escolhidas para denominar o projeto, estão justificadas na compreensão de que a História já está contada, de certa forma, na produção historiográfica. No entanto, a proposta é recontá-la em outra perspectiva, ou seja, a partir dos conteúdos históricos que estão presentes, principalmente, nos documentos em estado de arquivo familiar e na cultura experiencial dos alunos.

As referências teóricas do campo da Didática e da História, ao mesmo tempo em que têm orientado as atividades com os professores para organizar o trabalho de coleta de documentos pelos alunos, e seu uso em sala de aula, permite colocar em prática alguns princípios na produção de materiais didáticos que se diferenciam daqueles tradicionalmente produzidos. Tratando os conteúdos tematicamente, buscou-se construir estes materiais de forma a estabelecer maior interatividade entre os alunos leitores e 0 texto, e de forma a explorar uma pluralidade de fontes, justificada teoricamente pela renovação do conceito de documento histórico.

Pensando-se tanto na elaboração de aulas, como na produção de materiais, é importante destacar o papel desempenhado pelas atividades que foram denominadas de captação de conteúdos a serem ensinados. Trata-se de um conjunto de provas a serem resolvidas pelos alunos, voltadas à coleta de dados e informações sobre a história local, de forma semelhante a uma gincana, cujo objetivo é envolver a comunidade escolar de forma mais ampla.

A realização das atividades de captação de conteúdos por meio da gincana procura identificar fontes documentais, principalmente nos arquivos familiares, ao mesmo tempo em que busca sensibilizar a comunidade para contribuir nesta tarefa, permitindo 0 acesso a documentos pessoais e às suas memórias. Do ponto de vista metodológico, a organização dos conteúdos tem sido norteada por grandes temas como população, trabalho, cultura.

Dentro dos pressupostos teóricos assumidos, a investigação é proposta como atividade ou estratégia de ensino (IGLESIAS\&PEREZ, 1994) a qual pode ser relacionada com estudos da toponímia, da estatuária e dos documentos orais, por exemplo. Alunos e professores se organizam para localizar e coletar documentos, gravar entrevistas e depoimentos, registrar histórias contadas na localidade, descobrir e registrar manifestações da cultura e do lazer da localidade. Todo este acervo passa a compor um conjunto significativo de materiais extremamente valiosos para o estudo do conteúdo histórico trabalhado. 
A produção do conhecimento histórico em sala de aula foi pensada e planejada como metodologia de ensino (ZARAG0ZA, 1989). Alunos e professores desenvolvem na sala de aula, atividades de ensino e aprendizagem sobre os temas pesquisados, analisando documentos iconográficos e escritos, discutindo e comparando depoimentos colhidos, buscando articular seus conhecimentos com informações e dados coletados e também com o conhecimento histórico já produzido, construindo um certo tipo de conhecimento histórico qualitativamente diferente, o saber histórico escolar.

0 conjunto de atividades desenvolvidas no projeto, aquelas que tomam a investigação como atividade ou estratégia de ensino e as que incorporam 0 processo de produção do conhecimento histórico como método de ensino, permitiram que se colocasse em discussão a formação da consciência histórica dos alunos. Segundo Rüsen (1992), a consciência histórica trata-se de "um pré-requisito necessário para a orientação em uma situação presente que demanda ação". Isto significa que a consciência histórica funciona como um "modo específico de orientação"nas situações reais da vida presente, tendo como função específica ajudar a compreender a realidade passada para compreender a realidade presente. (p.28).

Desse ponto de vista, a consciência histórica dá à vida uma "concepção do curso do tempo", trata do passado como experiência e "revela o tecido da mudança temporal no qual estão amarradas as nossas vidas, bem como as experiências futuras para as quais se dirigem as mudanças"(p.29). Essa concepção molda os valores morais a um "corpo temporal", transformando esses valores em "totalidades temporais".

Assim, segundo Rüsen, a consciência histórica relaciona "ser" e "dever" em uma narrativa significativa que toma os acontecimentos do passado com o objetivo de tornar inteligível o presente e conferir uma expectativa futura a essa atividade atual. Portanto, a consciência histórica tem a "função prática"de dar à realidade uma direção temporal, uma orientação que pode guiar a ação intencionalmente por meio da mediação da memória histórica (p.29).

0 trabalho desenvolvido no projeto, e o processo de reflexão sobre 0 conjunto de atividades propostas, permitiram explicitar alguns princípios básicos que poderão nortear o ensino de História. Um primeiro princípio fundamental é que, ao buscar documentos, ao entrevistar moradores, ao percorrer as ruas 
em busca das casas mais antigas, os alunos se surpreenderam e puderam compreender que a História não se retringe ao conhecimento veiculado principalmente pelos manuais didáticos, instrumento que tem imposto um conhecimento histórico, via de regra, sem sujeito; que o conteúdo da História pode ser encontrado em todo lugar, e que o conhecimento histórico está na experiência humana.

0 segundo princípio, de natureza metodológica, está relacionado ao fato de que os alunos e os professores puderam identificar os indícios (conteúdos) da experiência humana em diferentes formas: a) na realidade cotidiana; b) na tradição; c) na memória; d) no conhecimento histórico sistematizado.

Um terceiro princípio deriva do entendimento de que a experiência humana apreendida, nessa perspectiva indiciária, não possui apenas uma dimensão localizada (bairro, cidade), mas identifica-se e articula-se com as experiências de outras pessoas, de outras épocas.

A sistematização dos três princípios selecionados indica que novas formas de captação e didatização dos conteúdos a serem ensinados em História contribuem para o desenvolvimento da consciência histórica crítico-genética, que supera, mas não exclui formas tradicionais de consciência histórica. ${ }^{6}$

Ao se depararem com conteúdos que evidenciam formas tradicionais ou exemplares de construção de narrativas da história da localidade, apreendidas sob a forma de depoimentos orais, documentos escritos ou iconográficos, os alunos se apropriam deles de maneira qualitativamente nova, recriando-os a partir de suas próprias experiências.

Estas novas apropriações e recriações da história da localidade evidenciam a possibilidade que o ensino de História tem de formar a consciência histórica crítico-genética. Estes conceitos tomados de Rüsen $(1992 ; 2001)$ apontam para 0 fato de que a construção da consciência histórica crítica exige conteúdos que permitam o desenvolvimento de uma argumentação histórica crítica, de uma contra narrativa, na medida em

6 Em Rüsen (1992), são quatro tipos de consciência histórica: tradicional (a totalidade temporal é apresentada como continuidade dos modelos de vida e cultura do passado); exemplar (as experiências do passado são casos que representam e personificam regras gerais da mudança temporal e da conduta humana); crítica (permite formular pontos de vista históricos, por negação de outras posições); e genética (diferentes pontos de vista podem ser aceitos porque se articulam a uma perspectiva mais ampla de mudança temporal, e a vida social é vista em toda a sua complexidade). 
que eles buscam a mobilização, não de todo o passado, mas de experiências específicas do passado. A partir do seu presente e de sua experiência, alunos e professores se apropriam da História como uma ferramenta com a qual podem romper, destruir e decifrar a linearidade histórica, fazendo com que ela perca 0 seu poder como fonte de orientação para 0 presente.

Confrontando conteúdos encontrados nos livros e manuais com outros encontrados por eles em atividades de captação, alunos e professores podem adquirir procedimentos que fazem com que tomem consciência de que 0 sentido do passado não se encontra somente na perspectiva da continuidade, mas também e principalmente, da mudança. Como afirma Rüsen (1992), a mudança temporal é despojada do seu aspecto ameaçador e se transforma no caminho em que estão abertas as opções para que a atividade humana crie um novo mundo. 0 futuro supera o passado em seu direito sobre o presente, um presente que passa a ser conceitualizado como uma intersecção, uma transição dinâmica. Assim, a consciência histórica passa a representar o passado como acontecimentos mutantes onde as formas mudam, paradoxalmente, para manter o seu próprio desenvolvimento. A própria permanência se torna dinâmica.

0 Projeto Recriando a História tem possibilitado concretizar, na formação continuada de professores, os princípios teórico-metodológicos da transposição didática (CHEVALLARD, 1997; DEVELAY, 1999), considerando-se:

a. o conhecimento histórico, ou seja, o saber a ser ensinado, encontrado nos manuais, nos vestígios e indícios documentais e na experiência cultural dos alunos;

b. o saber ensinado, ou seja, a ação dos professores em sala de aula, com 0 apoio dos materiais de ensino produzidos em conjunto com os professores;

c. o saber aprendido, isto é, a relação que os alunos estabelecem com 0 conhecimento histórico, compreendendo como algo que é diferente do simples acúmulo de informações.

A avaliação do Projeto, na perspectiva processual, tem permitido constatar uma alteração de natureza qualitativa em relação ao conhecimento: ao vivenciar elementos do método de produção do conhecimento histórico e da pesquisa como atividade de ensino, como parte de seu processo de formação continuada, os professores têm aprendido 
a encontrar o conteúdo nas diferentes formas da História e também a trabalhar com estes conteúdos em sua sala de aula.

Entende-se, neste caso, que a investigação com fins didáticos pode ser uma atividade inerente ao ofício de professor, quando pensada na relação com o método de pesquisa das ciências de referência e não como uma mera atividade de pesquisa. 0 fato de trabalhar com a metodologia de pesquisa específica de uma área de conhecimento - e não com a pesquisa genericamente entendida - fez com que os professores pudessem vivenciar e compreender uma determinada concepção de História, além de retomar o caminho que mostra 0 processo de produção do conhecimento histórico.

Trata-se, aqui, da possibilidade que se tem de aproximar o professor das formas como são produzidos os saberes, permitindo que ele se aproprie e/ou construa processos pelos quais esses saberes possam ser aprendidos. E, nessa direção, torna-se possível compreender que a forma pela qual se produz 0 conhecimento histórico hoje não é a mesma dos historiadores do século XIX e que, portanto, a forma de ensinar história não será a mesma também.

Outro aspecto a ser destacado diz respeito às possibilidades abertas ao professores, sujeitos que ensinam, de estabelecerem novas relações com os saberes a serem ensinados. Os procedimentos de identificação, seleção e proposição de conteúdos de ensino, no caso da História, puderam também ser desenvolvidos pelos próprios professores, a partir do seu envolvimento com a sua realidade histórica, pressuposto básico para o trabalho de produção do conhecimento histórico.

Tais aprendizagens têm sido possíveis para o grupo de professores envolvidos no Projeto, a partir de um conjunto de atividades que foram sendo desenvolvidas e discutidas do ponto de vista teórico. No entanto, deve-se compreender que tais conhecimentos novos não são transpostos de forma direta para o conjunto de saberes que os professores devem mobilizar e articular ao preparar e desenvolver suas aulas de História, cotidianamente, dando uma nova dimensão à idéia de que há também um processo de transformação dos saberes a serem ensinados em saberes ensinados.

Os materiais de apoio produzidos para servir de referência ao trabalho foram incorporados, em muitos casos, ao conjunto de outros materiais já disponíveis na escola e que, necessariamente, não se organizam a partir dos 
mesmos referenciais teórico-metodológicos. Na mesma perspectiva, ainda que a importância de usar documentos no ensino de História e também a forma pela qual podem ser usados fosse conhecida pelos docentes, isto não significou uma incorporação dessas metodologias e estratégias em todas as aulas de História. Tais constatações reafirmam a relevância dos processos de desenvolvimento profissional de professores.

É importante destacar, por fim, que existem elementos novos a considerar quando são elaboradas novas propostas curriculares para os saberes a serem ensinados, elementos estes pertinentes aos próprios saberes, aos saberes presentes nos materiais de apoio didático, ou mesmo nos saberes presentes nas atividades produzidas pelos alunos.

Tais elementos, explicitados nas investigações realizadas no contexto do Projeto Recriando a História e apontados nos princípios aqui identificados, resultaram de reflexões que podem ser compreendidas como primeiras aproximações e que apontam para a necessidade de aprofundar a compreensão sobre a forma como os saberes a serem ensinados se transformam em saberes ensinados e em saberes aprendidos. Em sua atual etapa de investigação, o Projeto Recriando a História tem como objetivo investigar as mudanças conceituais identificadas nos alunos, a partir dos trabalhos desenvolvidos.

Tais investigações podem contribuị para, como afirma Zaragoza (1989), explicitar a historicidade do próprio conhecimento histórico e fazer com que a História deixe de ser tratada como dogma.

\section{Bibliografia}

ARTIÈRES, Philippe. Arquivar a própria vida. Estudos históricos: arquivos pessoais. Rio de Janeiro: Fundação Getúlio Vargas, v.11, n.21, 9-34, 1998.

ARTHUR, James/PHILLIPS, Robert. Issues in history teaching. London: Routledge, 2000 .

BARCA, Isabel. 0 pensamento histórico dos jovens. Braga: Uniminho, 2000

Perspectivas em educação histórica. Braga: Uniminho, 2001

BOURGUiGnON, Lucien. Histoire et didactique. Les défis de la complexité. Paris : CNDP, 1998. 
CHEVALLARD, Yves. La transposición didáctica: del saber sabio al saber a ser ensinado. Argentina: Aique Grupo Editor S.A., 1997.

COUSINET, Roger. L'enseignement de l'Histoire et l'éducation nouvelle. Paris :PUF,1950.

DEVELAY, Michel. De l'apprentissage à l'enseignement. Paris : ESF, 1999

FORQUIN, Jean-Claude. Escola e Cultura: as bases sociais e epistemológicas do conhecimento escolar. Porto Alegre: Artes Médicas, 1993.

FREIRE, Paulo. Educação como prática da liberdade. Rio de Janeiro: Paz e Terra, 1967. Pedagogia do Oprimido. Rio de Janeiro: Paz e Terra, 1970.

. Pedagogia da Esperança: um reencontro com a Pedagogia do Oprimido. São Paulo: Paz e Terra, 1992.

GERMINARI, Geyso. O uso metodológico de documentos em estado de arquivo familiar no ensino de História nas séries iniciais da escola fundamental. Curitiba, 2001. 161 f. Dissertação (Mestrado em Educação) - Programa de Pós-Graduação em Educação. Universidade Federal do Paraná.

HAYDN, T. / ARTHUR, J./ HUNT, M. Learning to teach History in the secondary school. London: Routledge, 2001.

IGLESIAS, F. Javier Mérchan y PÉREZ, Francisco F. Garcia. Una metodología basada en la idea de investigación para la enseñanza de la historia. In. Aisenberg, B./ Alderoqui,S. (comps.) . Didáctica de las ciencias sociales. Aportes y reflexiones. Buenos Aires: Piados Educador,1994.

LAUTIER, Nicole. Enseigner l'Histoire au Lycée. Paris : Armand Colin,1997

LEDUC,J./MARCOS-ALVAREZ, V./ LE PELLEC, J. Construire l'Histoire. CRDP MidiPyrénées : Bertrand-Lacoste, 1998

MICHAUX, Madeleine. Enseigner l'Histoire au Collège. Paris : Armand Colin,1997

MONIOT, Henri. Didactique de l'Histoire. Paris : Nathan,1993

OSSANA, Edgardo. Una alternativa en la enseñanza de la Historia: el enfoque desde lo local, lo regional. In VASQUEZ, Josefina Z. Enseñanza de la Historia. Buenos Aires, 1994. (Colección INTERAMER 29).

PRATS, Joaquin. Enseñar Historia: Notas para una didáctica renovadora. Mérida: Junta de Extremadura, 2001 
PROENÇA, Maria Candida. Ensinar/aprender história: questões de didáctica aplicada. Lisboa: Livros Horizonte, 1990.

ROMER0, Luis Alberto. Volver a la Historia. Buenos Aires: Aique, 1998.

RUSEN, Jorn. El desarollo de la competência narrativa en el aprendizaje histórico. Una hipótesis ontogenética relativa a la consciencia moral. Propuesta Educativa. Argentina, n.7, out/92.

Razão Histórica. Brasília: Unb, 2001.

SACRISTÁN, J.Gimeno; PEREZ GOMEZ, A . Compreender e transformar o ensino. Porto Alegre: ArtMed, 1998.

TERRISSE, André (ed.). Didactique des disciplines. Bruxelles: De Boeck Université,2001.

THOMPSON, E.P. A miséria da teoria ou um planetário de erros. Uma crítica ao pensamento de Althusser. Rio de Janeiro: Zahar, 1981.

Historia Social y Antropologia. México: Instituto Mora, 1997

TREPAT, Cristofol-A. Procedimientos en Historia. Un punto de vista didáctico. Barcelona: Grao, 1995

ZARAGOZA, Gonzalo. La investigación y la formación del pensamiento histórico del adolescente. In. CARRETERO/M.;POZO,J.I.; ASENSIO, M. (compiladores). La enseñanZa de las Ciencias Sociales. Madrid: Visor Distribuciones, 1989. 


\title{
The historical work in the classroom
}

\begin{abstract}
Which is the place and the meaning of the research in the teacher's formation? What sense and usefulness has the research in daily practice of the History teacher? This text presents reflections on these themes, telling partial results of researches, whose general objective is to recover the process of construction of the History teaching method, starting from the dialogue among the General Didacticism (Develay, 1999; André, 1995) and the Specific Didacticism of the History (Prats, 2001; Moniot, 1993; Bergman,1990 and Rusen, 1987). These results focus some elements of the studies accomplished in the extent of the bibliographical research, the one that allowed pointing out indications of how the theme is seen by the literature destined to teachers' formation; and in the perspective of the field work, what produced subsidies for reflections concerning the teacher's of History daily practice, rendered in the project Recreating Histories, which has been developed by the researchers in schools of the metropolitan area of Curitiba, since 1997. To now, the results allow to reaffirm the presupposition that, to transmit contents and to assume the investigation perspective are not excluding alternatives.
\end{abstract}

Key-words: History teaching, didatics, local history, teachers' formation 